\title{
Practice of Software Engineering Specialty in the Perspective of Application Transformation
}

\author{
Bin Wen, Xiuhong Zhang, Xueping Zhang, Bing Han, Mousong Fu, Ziqiang Luo \\ School of Information Science and Technology, \\ Hainan Normal University, \\ Haikou, China \\ Email: binwen@hainnu.edu.cn
}

\begin{abstract}
The new era needs new achievements and new coordinates, and the application transformation construction at the provincial level determines the new direction and goal for the software engineering major. This paper comprehensively discusses the construction idea and specialty construction plan of the pilot project of software engineering application transformation in Hainan Province as the sole provincial project, focusing on the experience and practice of training mode, university-enterprise cooperation and curriculum resources construction. The construction results are expected to provide a talent training road map and an effective example for the development of science and technology and education in Hainan province.
\end{abstract}

Keywords-specialty construction; Software engineering; application-oriented transformation; training mode

\section{INTRODUCTION}

"Time flies, such as foal." Time passed quickly, Hainan Normal University software engineering provincial application transformation project has been established for a year. In the past one year, the software engineering specialty construction team has used the spare time, winter and summer vacations in accordance with the requirements of the task under the circumstance of arduous daily teaching and scientific research tasks, and has been actively promoting the dedication of moral education and all for the students.

Through this specialty application transformation and construction, the construction's positioning and development goals are clearly proposed. Namely, "cultivate applied talents who adapt to the needs of local economic and social development with solid foundation, solid skills and strong social adaptability, and build the software engineering major into an applied specialty with distinctive characteristics and important influence in Hainan Province."

The training goal is to produce the innovative engineers who master the basic theories, knowledge, methods and skills in software engineering and related fields of expertise. The purpose of this paper is to study the practice and roadmap of the application transformation and construction of software engineering specialty. We mainly focus on talent training and curriculum system construction, as well as the construction of curriculum resources. The rest of the article is organized as follows. Section II includes the optimization of talent training and the program for the construction of the curriculum system. Section III introduces the construction and practice of the case base of curriculum resources. Conclusions with main contributions of practical experience are also touched upon in section IV.

\section{OPTIMIZATION OF PERSONNEL TRAINING AND CURRICULUM SYSTEM}

The specialty is related to the professional needs of the society and it is the performance of the professional classification of the society in the training of talents in colleges and universities. The application transformation of software engineering major at Hainan Normal University is guided by Hainan Province's "Suggestions on promoting the transformation of undergraduate universities to the application type".

The implementers of specialty construction are teachers, and students are the display of specialty construction. When we first got the provincial application transformation major, we immediately organized the whole department teachers to participate in the preparation of the task book, and closed a day to discuss the writing content and theme of the application transformation specialty task book. Regardless of the framework structure or construction connotation, the task book as a program of action has been recognized by the relevant experts of the school, passed the review of the school and submitted to the provincial education department. At the beginning of the spring semester of 2017, all the professional teachers held the starting ceremony and workshop of the construction project.

The overall objectives of the application transformation and construction identified here are as follows.

Strive to use three years or so to guide the software engineering profession to be guided by market demand, industry, and job requirements, and further clarify specialty orientation. With system innovation, ability development, university-enterprise cooperation, and double-master-type teacher team as the main development path, we will continue to innovate the application-oriented training model and improve the quality of applied talents. We will gradually integrate into the modern vocational education system and build a cross bridge that can organically connect the industry and the society with the training of talents.

Table I is the detailed implementation goal of software engineering application transformation. 
We make full use of the time window of the 2016 edition of the training program, and put the concept of applied experience and employment channels, providing jobs for students.

TABLE I: The detailed implementation goal of software engineering application transformation

\begin{tabular}{|c|l|l|}
\hline No. & Accomplished goals & Complete display degree \\
\hline 1 & $\begin{array}{l}\text { Define the position of specialty development and formulate the reform } \\
\text { plan for specialty construction }\end{array}$ & Completing a new version of the training program program. \\
\hline 2 & $\begin{array}{l}\text { Establishing the system of industry and enterprise to participate in } \\
\text { specialty construction }\end{array}$ & $\begin{array}{l}\text { Establishing the innovation mechanism of industry, university and } \\
\text { research }\end{array}$ \\
\hline 3 & Innovative talents training mode based on professional demand & The training mode of $1+2+1$ \\
\hline 4 & Building a curriculum system based on professional competence & Completing the construction of case base resources \\
\hline 5 & $\begin{array}{l}\text { Strengthening the construction of practical training base for experi- } \\
\text { mental practice }\end{array}$ & Optimizing the training base of students' practice \\
\hline 6 & Explore the management system under the new cultivation mode & Compilation of management system \\
\hline 7 & Building a "double-master-type" teacher team & $\begin{array}{l}\text { Everyone completes the double-master-type certification or training } \\
\text { Funning mechanism runs through the whole process of students' } \\
\text { training }\end{array}$ \\
\hline 8 & \begin{tabular}{l} 
Forming the joint operation mechanism of the university and the \\
\hline
\end{tabular}
\end{tabular}

transformation into the training program, and make the top level design of the specialty construction.

- According to the goal of applied specialty construction, in the training plan, it is clear that specialty is to train high-quality, practical and internationally competitive application and innovative software engineering professionals.

- In accordance with the "ability training" as the core of the training target of applied talents.

The opening of each course corresponds to the completion of a number of ability training tasks. We expect to establish a two-dimensional relationship matrix for each course and the ability to graduate. The corresponding relationship between all courses and graduation requirements is set up, emphasizing the training of students' professional skills and ability to solve practical problems.

\section{A. Training Mode: $1+2+1$ (abbreviated as 121)}

Based on professional demand, we explore the training mode of 121 universities and enterprises in depth cooperation and customization.

"1"-According to Hainan Normal University's major enrollment and specialty diversion policy, students first received general education and basic education of major disciplines in the first year, and focused on strengthening the training of mathematics and programming skills.

" 2 " - The students entered the professional learning from second years, two years by the school according to the market demand of software talents occupation, professional basic courses of software engineering technology to realize software talents, deep knowledge and thick foundation, have the ability to adapt to the rapid development of software technology and further study. At the same time, the systematic study of professional development courses and the introduction of some enterprise curriculum resources to realize the cooperation and docking of the campus and the enterprise.

"1" - Refers to the fourth school year to enter the training base for training and practice, cooperation with enterprises and instruct the students to complete the graduation design and thesis defense, some enterprises can also be paid internship, graduation and employment to achieve seamless docking, the use of software enterprise rich industry

\section{B. Building a Multidimensional and Integrated Practical Teaching System based on the Standard of Professional Ability} follows.

The guiding principles of the curriculum system are as

- Closely adhere to the needs of the enterprise, and make clear the orientation of the students' career.

- To train applied talents as the goal, project - driven, "quasi-employee" work, study and life.

- Take the project as the driving force, implement the CDIO engineering education model, "learning combining with practice", and accumulate the project experience.

Compared with international similar majors, referring to software engineering knowledge system standard, guided by professional demand of software talents market, modular curriculum is adopted to optimize teaching contents. The construction of "Learning - Training - relearning - and then training" is built on the core of the engineering practice. It is mainly divided into three stages of practice teaching system.

The first stage is the basic course experiment. We should pay attention to the close relationship between the basic knowledge and the basic theory and the experimental link, and pay attention to the mastery of basic skills and the training of basic skills.

The second stage is that the professional curriculum should be combined with the course experiment + training. On the basis of basic skills practice, invite software company lecturers into the classroom, integrate real cases of software companies into classroom, and train students' comprehensive practical ability.

The third stage is professional knowledge learning and comprehensive practice training based on professional direction. It emphasizes the cultivation of students' practical ability and innovative consciousness and their personality development and quality improvement. At this stage, the emphasis of engineering practice is to enhance students' comprehensive quality and professional quality of software engineering, and enhance the competitiveness of employment at the same time of completing the graduation project. 


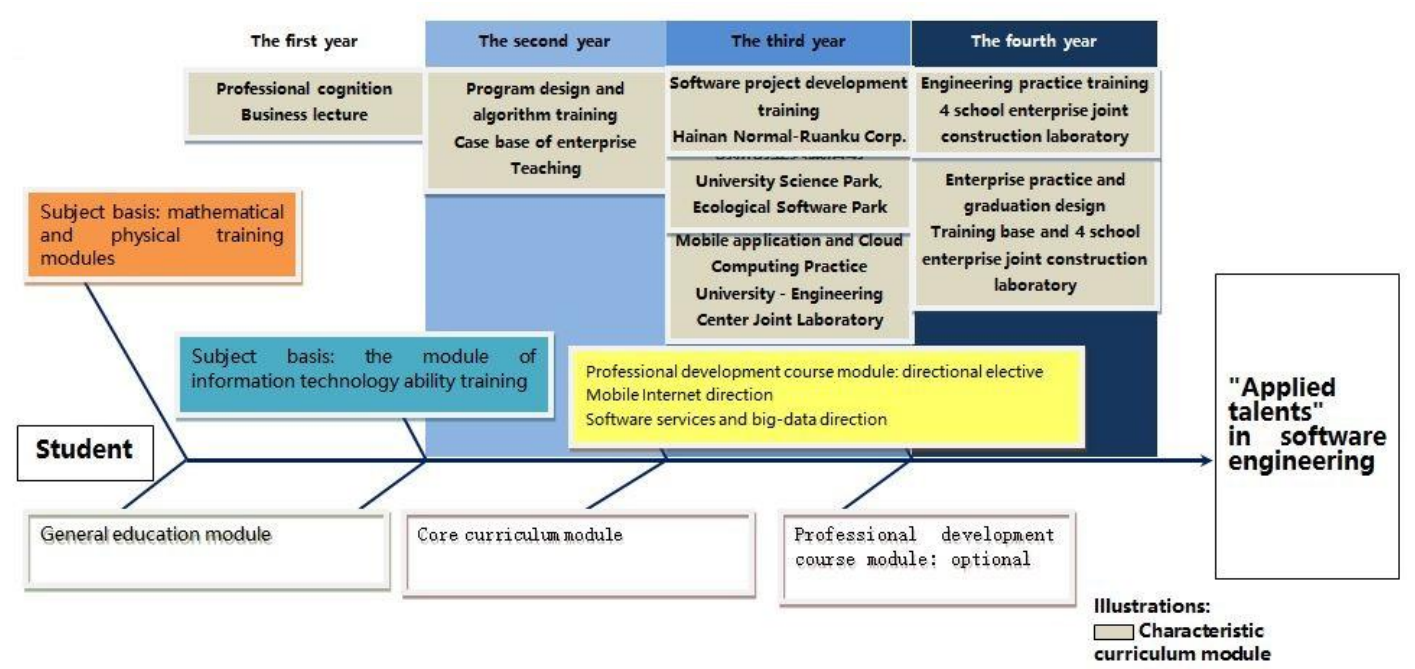

Figure 1. Main course system of software engineering specialty

\section{Expanding the Practice Platform Space to Realize the Cultivation of Deep Cooperation and Customization with Enterprises}

We put the students' fourth years of graduation practice and graduation design and their graduation defense directly into the deep cooperative software enterprise, and cooperate with the enterprise in depth. The students in software enterprise practice, deep experience of enterprise culture of learning industry occupation skills and occupation experience, development of software application through the actual participation of enterprises, and effectively improve the students' ability to solve practical problems, so as to realize the seamless graduation and employment.

1) Reform of software engineering teaching methods

a) Re-optimize cleaning and reform teaching content.

Drawing on the core concept of CDIO International Engineering Education, the teaching content of each course in the curriculum system is optimized, and a new round of syllabus for each course of software engineering is formulated.

b) Update the teaching mode to stimulate students' subject consciousness.

Fully implement the teaching reform of each course, advocate teacher-led, student-centered, discussion style, inquiry style, discovery style, focus on students' innovative ability, entrepreneurial ability, leadership ability, team ability, communication and writing ability, and application of professional Skills to comprehensively solve practical problems.

c) Reform the teaching means and construct the threedimensional network learning resources.

Make full use of the rich teaching resources of the Internet era, such as micro-curriculum, MOOC curriculum resources, and online course cloud platform, so that students can acquire learning information resources from multienvironments, multi-positions, and multi-angles, flip classrooms, and achieve autonomous learning, based on issues. The study, task-based learning and practice comprehensively improve the overall quality and ability of students.

d) Reform the assessment mechanism and focus on process assessment

Emphasizes the evaluation of students' learning process, and focuses on students' learning ability, practical ability, innovation ability, team ability, communication ability and other comprehensive ability evaluation, and builds an objective and scientific course evaluation system.

2) Practice teaching construction program

In addition to the curriculum experiments in different courses, according to the three ability training stages, combined with the school enterprise cooperation mode, the enterprise actual case is introduced, and the enterprise software engineer and project manager are set up, and three stages of capacity training practice course are set up respectively (Figure 2). In order to ensure the quality of the students' software engineers to meet the standard, the evaluation and assessment of the core competence are strictly observed.

In the first phase, a two-week "Programming and Algorithm Training" focused practice will provide multiple individual cases for practical training, involving high-level language programming and object-oriented programming and other professional courses, the focus is to consolidate Program design core curriculum knowledge to develop students' application problem analysis and modeling capabilities.

In the second phase, the four-week "Software Project Development Training" will be practiced in a centralized manner. It will provide multiple comprehensive examples for practical training. It covers professional structures such as data structures, databases, and operating systems. The field involves the Java Web Development, Android App development, J2SE development, etc. The focus of practice is on software development and application of software engineering technology. 


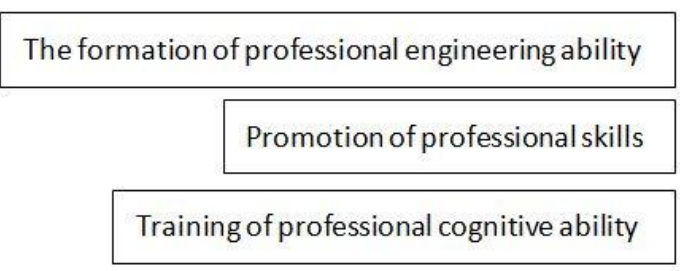

Figure 2. Three stages of students' practical ability

In the third stage, students enter the company for a 12week internship, and at the same time combine the contents of the internship for an 8-week graduation project. The focus of practice is to strengthen students' overall quality of software engineering and professional comprehensive quality. Graduation thesis (design) can be used in schools and enterprises and dual tutors, the topics are mainly from the key issues in the actual project facing the needs of social applications. Graduation design is the main part of the graduation reply. The standardization of the design program, the reliability of the software system, the social demand of the product, and the quality of the project organization are used as the evaluation criteria for student achievement, and the graduation design quality is effectively improved.

The goal is to build a practical curriculum system that develops students' professional practice abilities at a level and enhances their practical ability level by level. We divide the practical ability of students into three levels and carry out targeted training at different levels.

In order to better cultivate students' professional application ability, in addition to training within the curriculum system, they should also provide opportunities for students to improve their ability outside the curriculum system.

Strengthen cooperation with enterprises, build a variety of types of practice bases, provide targeted internship opportunities for each competency phase of the students, further strengthen capacity development at different levels, and integrate the entire internship process with the university's four years' time. Using the winter and summer vacations to provide students with internship opportunities, so that students come in contact with and understand the
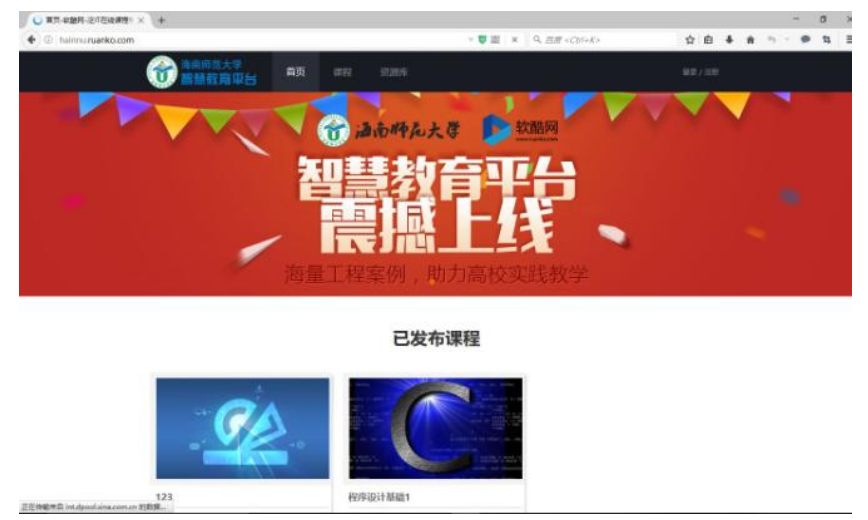

Figure 3. Curriculum case repository

company this morning, establish their own professional ability in the future development direction.
Give full play to the initiative of students, be guided by innovation and competition, guide students in extracurricular time, self-learning and self-cultivation, and enhance students' professional application ability through competition projects or innovation and entrepreneurship projects.

\section{RESOURCE CONSTRUCTION}

The practical teaching and training link set up in the software engineering undergraduate professional training program requires a number of digital case resources for industry development. After market research and program optimization, we collaborated with ruanku Corp. to jointly develop the "Talent Practice Capacity Development Solution" and a customized curriculum case repository.

The case repository is deployed in the school's data center (Figure 3). As a digital resource for the entire school, it can fully meet the online and offline interactive fusion model of software engineering teachers and students.

\section{CONCLUSIONS}

The paper summarizes our experience and practice in specialty construction, focusing on talent training plan design and curriculum system arrangement, as well as the achievement of curriculum assistance case library construction based on the perspective of application transformation.

\section{ACKNOWLEDGMENT}

This research has been supported by Hainan Education and Teaching Reform Major Project (Hnjgzd2014-07), Hainan Provincial Higher Education and Teaching Reform Research Project (HNJG2014-27), Hainan Applied Transformation Specialty (Software Engineering) Construction Project.

\section{REFERENCES}

[1] Sub Committee of Teaching and Instruction for Software Engineering Major of the Ministry of Education, Major norms for software engineering in Colleges and Universities. Higher Education Press, 2011.

[2] C. Jie, "The reform and innovation of the comprehensive practical skill competition for college students in applied universities software engineering as an example," Education Modernization, vol. 4, no. 47, pp.62-64, 2017.

[3] T. Lin and Z. Yingbo, "The design of the pilot framework for the transformation of the applied undergraduate software engineering specialty," Computer Education, no. 11, pp. 78-81, 2017.

[4] R. Yu and H. Xu, "The reform and practice of software engineering teaching mode for application oriented talents training - qingdao agricultural university as an example," Higher Agricultural Education, no. 3, pp. 73-76, 2016.

[5] W. Bin, Z. Xiuhong, W. Lihua, H. Bing, and L. Ziqiang, "Top-level design and practice arrangement for application innovation oriented software engineering personnel training," Computer Education, no. 20, pp. 5-8, 2015. 